\title{
Ionic Liquids: Future Solvents and Reagents for Pharmaceuticals
}

\author{
Muhammad MoniruZZAMan ${ }^{1}$ and Masahiro Goto ${ }^{2,3}$ \\ ${ }^{1}$ Department of Material and Energy Science, \\ Graduate School of Environmental Science, Okayama University, \\ 3-1-1, Tsushima-naka, Okayama-shi, Okayama 700-8530, Japan \\ ${ }^{2}$ Department of Applied Chemistry, Graduate School of Engineering, \\ Kyushu University, \\ 744, Moto-oka, Fukuoka-shi, Fukuoka 819-0395, Japan \\ ${ }^{3}$ Center for Future Chemistry, Kyushu University, \\ 744, Moto-oka, Fukuoka-shi, Fukuoka 819-0395, Japan
}

Keywords: Ionic Liquids, Sparingly Soluble Drugs, Active Pharmaceutical Ingredients (APIs), Transdermal Delivery, Antimicrobial Activity

\begin{abstract}
The pharmaceutical industries are undoubtedly experiencing a series of challenges. One of these is the administration of solid form of many drugs due to many well known drawbacks including low solubility, polymorphic conversion and low bioavailability. Such problems are further aggravated when drug molecules or starting materials for synthesis of drugs are insoluble or sparingly soluble in aqueous media and most of pharmaceutical acceptable organic solvents. To overcome these problems, some times, highly polar organic solvents including pyridine, dimethylformamide (DMF) and $N$-methylpyrrolidone (NMP) which are not considered as environmental benign solvents have been used. These restrictions demand superior solvent systems and/or new drug forms that can be used as reaction media to avoid volatile organic solvents and/or as new forms of drugs. Much effort is being invested in such approaches to find new delivery technologies or development of new controlled-release dosage forms. In recent years, ionic liquids (ILs) that are salts of low melting point and consist only of ions have been increasingly exploited as solvents and/or (co)solvents and/or reagents in a wide range of pharmaceutical applications due to their tailor-made chemical, physical and biological properties. Studies have shown that ionic liquid-assisted drug carrier or active pharmaceutical ingredients (APIs) synthesized as IL form or many drug compounds produced using ILs as reaction media provide many unique and attractive properties compared to conventional counterparts. Furthermore, ILs could be employed as potential antimicrobial agents for various microorganisms. The aim of this article is to summarize the efforts placed on using ionic liquids in pharmaceutical applications.
\end{abstract}

\section{Introduction}

Room temperature ionic liquids (RTILs), an interesting class of tunable and designer solvents with the extremely low vapor pressure have been extensively used as a potential replacement for toxic, hazardous, flammable and highly volatile organic solvents (VOSs) (Welton, 1999; Rogers and Seddon, 2002). Ionic liquids (ILs) are composed entirely of ions (generally consisting of bulky asymmetric organic cations such as alkylimidazolium $\left[\mathrm{R}_{1} \mathrm{R}_{2} \mathrm{IM}\right]^{+}$, alkylpyridinium $[\mathrm{RPy}]^{+}$, tetraalkylammonium $\left[\mathrm{NR}_{4}\right]^{+}$or tetraalkyl-phosphonium $\left[\mathrm{PR}_{4}\right]^{+}$and anions (see Figure 1)), and are liquids at ambient or far below ambient temperatures. In fact, the asymmetry of the cation is believed to be responsible for the low melting temperatures. Based on the solubility of ILs in water,

Received on January 24, 2011; accepted on March 30, 2011

Correspondence concerning this article should be addressed to M. Goto (E-mail address: m-goto@mail.cstm.kyushu-u.ac.jp).
ILs can be divided into two categories: hydrophobic (water immiscible) and hydrophilic (water miscible). This water miscibility generally depends on the anions of ILs. ILs have many attractive physicochemical properties such as negligible vapor pressure, multiple solvation interactions with organic and inorganic compounds (Anderson et al., 2002), excellent chemical and thermal stability (Kosmulski et al., 2004), high ionic conductivity and a wide liquid temperature ranges which draw the growing interest in both industrial and academic research laboratories. Most importantly, the properties regarded as the viscosity, hydrophobicity, density and solubility of ILs can be tuned by selecting different combinations of cations and anions, to customize ILs for specific demands. During the last decade, the interest in the ILs has increased significantly because of their potential as solvents and/or (co)solvents and/or reagents in a wide range of applications, including chemical engineering (separation, extraction and membranes) (Visser et al., 2001; Anderson and Armstrong, 2005), chemistry 


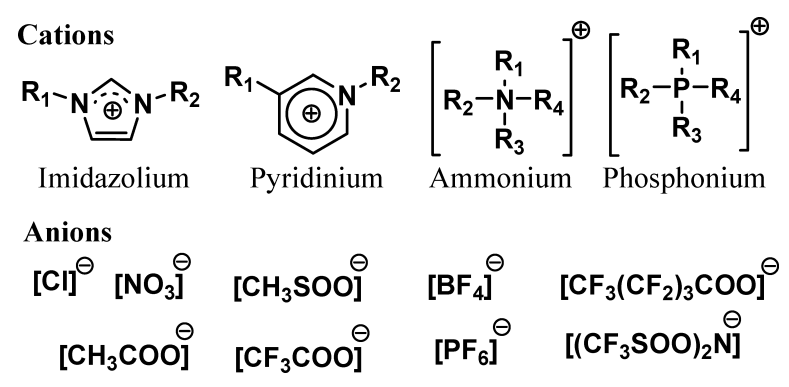

Fig. 1 Commonly used ions of ionic liquids

(organic synthesis, catalytic reactions, nanomaterial synthesis and polymerization reactions) (Welton, 1999; Harada et al., 2009), energy conversion (batteries, fuel cells and heat storage) (Belieres et al., 2006) and biotechnology (biocatalysis, biomolecules purification and biofuels production) (Rantwijk and Sheldon, 2007; Moniruzzaman et al., 2010a, 2010b). However, the use of ILs in pharmaceutical applications especially in medical applications is very limited, possibly due to the lack of information on their toxicity, purity, biodegradability and regulatory approval (Constable et al., 2007). However, various studies on such issues indicate that the toxicity of ILs does not preclude their use as pharmaceutical solvents (see Section 2 for details).

Promisingly, in the last few years, ILs have been increasingly exploited as solvents and/or materials in the field of pharmaceuticals with the possibility of improved performance such as improved solubility, stability and drug delivery (Hough et al., 2007; Jaitely et al., 2008; Carson et al., 2009; Bica et al., 2010; Moniruzzaman et al., 2010c). This review article presents a general overview of the potential approaches to use ILs in the field of pharmaceuticals.

\section{Necessity of ILs in Drug Formulations}

Drug formulations (e.g., solid and crystalline forms) that are poorly soluble in conventional solvents pose many serious problems. Low solubility is usually associated with poor absorption and bioavailability upon oral administration (Lipinski et al., 2001). In the pharmaceutical industry and in modern medicine, it is well known that many promising drugs that are sparingly soluble in conventional solvents never enter a formulation stage due to their poor solubility as well as difficulties in delivery. On the other hand, many substrates being used for synthesis for many valuable drugs such as nucleoside analogs have limited solubility in conventional solvents. In order to meet these challenges, approaches ranging from biological modification of drug compounds to the tailoring the delivery techniques have been used with various degrees of success. One conventional way to address the poor solubility of drugs in order to increase their performance is to use excipients polar organic solvents, such as pyridine, $N, N$-dimethylformamide (DMF) and dimethyl sulfoxide (DMSO) (Yalkowaky, 1981). However, the use of such organic solvents has many drawbacks. They are often volatile, flammable and toxic. Pharmaceutical ingredients must be free from all such traces. Furthermore, when these solvents are used as reaction media for synthesis of drugs, they make difficulty in recovery and reuse steps. In addition, the production of large quantities of waste products and/or waste disposal has to be considered. Considering the properties of ILs, it is highly desirable for ILs to be potential solvents for overcoming the problems mentioned above.

In fact, due to their tailor-made properties, ILs can dissolve complex molecules including biologically active compounds such as protein, nucleosides and amino acids under milder conditions (Fujita et al., 2005, 2006; Kumar et al., 2007; Fukaya et al., 2008). We believe that ILs tunable properties may allow the possibility for tailoring pharmaceutical solvents or use them in the synthesis for new drug forms with specifically desired properties that are effectively limited when water or molecular organic solvents are used. Fortunately, the use of ILs in drug delivery technologies, ILs as APIs and ILs as media for drug synthesis has just started.

\section{Toxicity and Biodegradability of ILs}

Although ILs are considered as "green solvents", their toxicological issue is still debatable. Regarding the use of ILs in pharmaceutics especially in medical application, most people think that the toxicological issue of ILs is the main challenge for its biological applications in drug delivery. In recent years, the cytotoxic, environmental, and microbial toxicity of the most common ILs have been studied extensively. The ability to finely adjust the biological properties of ILs by simply changing their anion/cation combination could be used to generate nontoxic ILs. Fortunately, in recent years, some reports have demonstrated that nontoxic ILs could be produced by selecting biocompatible organic cations and inorganic anions (Pernak et al., 2004a; Vidis et al., 2005; Wood and Stephens, 2010). The effect of $[\mathrm{bmim}][\mathrm{Cl}]$ on marine algae, or enzymes like acetylcholinesterase indicate that the IL was not acutely toxic $\left(\mathrm{EC}_{50} \approx 13 \mu \mathrm{M}\right)$ (Swatloski et al., 2004). More interestingly, some studies have shown low/negligible toxicity of some imidazolium based ILs towards Caco-2 cells (Jaitely et al., 2008) or female Wistar rats $\left(\mathrm{LD}_{50}=1400 \mathrm{mg} / \mathrm{Kg}\right.$ ) (Pernak et al., 2001). However, there is a lack of in vivo investigation on IL biouptake. It should be noted here that many useful and necessary chemicals are toxic: many pharmaceutical excipients such as DMSO and nonionic surfactants (e.g., polysorbate 80 ) display similar toxicities to what was observed in many ILs.

However, special care should be paid in selection of IL because the toxicity of ILs depends significantly on 
their cation and the alkyl side chain (Stolte et al., 2007). Generally, ILs synthesized with imidazolium cation are more toxic than phosphonium and ammonium based ILs (Jastorff et al., 2005). ILs with the benign cholinium cation were found to be highly biocompatible (Petkovic et al., 2010). For example, the cholinium alkanoates were less toxic than their corresponding sodium salts. On the other hand, the toxicity of ILs increases dramatically with the increase in the length of side chain. Additionally, it was found that the incorporation of ether groups into the ester side-chain significantly reduced the toxicity compared with alkyl ester derivatives (Morrissey et al., 2009). Hence, bulky cholinium, phosphonium or ammonium based ILs with the shorter side chains on the cation core would be safer/more useful ILs for pharmaceutical use.

To use ILs as solvents and/or reagents for drug formulations, ILs should preferentially exhibit good biodegradability with their low toxicity. Although toxicity evaluations of many ILs have been studied extensively, there are very few studies focused on biodegradation. Recently, much attention has been given to synthesis biodegradable ILs. Although ILs with a short alkyl chain appended in the cation have shown low toxicity, ILs containing short alkyl chains have proven resistant to biodegradation (Gathergood et al., 2004). Petkovic et al. (2010) have found that the biodegradation of ILs based on cholinium cation $\left[\mathrm{NMe}_{3}\left(\mathrm{CH}_{2} \mathrm{CH}_{2} \mathrm{OH}\right)\right]^{+}$undergo complete biodegradation under aerobic conditions, with a range of linear alkanoate anions $\left(\left[_{\mathrm{C}_{n} \mathrm{H}_{2 n}+1} \mathrm{CO}_{2}\right]^{-}\right.$, $n=1-9)$ in $P$. corylophilum cultures. It was observed that ILs with longer linear chain anions such as butanoate, pentanoate, hexanoate and octanoate were fully biodegradable, whereas ILs with short linear chain anions (e.g., ethanoate and propanoate) were not fully degraded. Another way to synthesize biodegradable ILs is with pyridinium core (Ford et al., 2010). However, biodegradeability is highly dependent on the side chains. Pyridinium ILs bearing ester groups in the 1- and 3-positions showed high levels of biodegradation under aerobic conditions and can be classified as "readily biodegradable'. In contrast, pyridinium ILs with linear alkyl chains showed significantly lower levels of biodegradability. Recently, a comprehensive tutorial review of biodegradable studies of ILs was published by Coleman and Gathergood (2010) in which they reported different routes for the preparation of ILs that are nontoxic as well as biodegradable.

\section{Ionic Liquids in Pharmaceuticals}

\subsection{Solubility of drug compounds in ILs}

A number of compounds having pharmacological activity have been found to be difficult to dissolve into aqueous solution and commonly used organic solvents. Although such compounds contain several polar groups in their molecular structure, they have been found to be
Table 1 Solubility of acyclovir in some commonly used ILs ${ }^{\mathrm{a}}$ at $25^{\circ} \mathrm{C}^{\mathrm{b}}$

\begin{tabular}{lc}
\hline \multicolumn{1}{c}{ ILs/solvents } & Solubility [wt $\%]$ \\
\hline$\left[\mathrm{C}_{1} \mathrm{mim}\right]\left[\left(\mathrm{CH}_{3} \mathrm{O}\right)_{2} \mathrm{PO}_{2}\right]$ & above $25 \%$ \\
{$\left[\mathrm{C}_{2} \mathrm{mim}\right]\left[\left(\mathrm{CH}_{3} \mathrm{O}\right)_{2} \mathrm{PO}_{2}\right]$} & above $15 \%$ \\
{$\left[\mathrm{C}_{2} \mathrm{mim}\right]\left[\mathrm{CH}_{3} \mathrm{COO}\right]$} & $10-12 \%$ \\
{$\left[\mathrm{C}_{2} \mathrm{mim}\right]\left[\mathrm{BF}_{4}\right]$} & insoluble \\
{$\left[\mathrm{C}_{2} \mathrm{mim}\right]\left[\left(\mathrm{CF}_{3} \mathrm{SO}_{2}\right)_{2} \mathrm{~N}\right]$} & insoluble \\
{$\left[\mathrm{C}_{4}\right.$ mim $]\left[\mathrm{PF}_{6}\right]$} & insoluble \\
{$\left[\mathrm{C}_{4}\right.$ mim $]\left[\mathrm{CH}_{3} \mathrm{CH}(\mathrm{OH}) \mathrm{COO}\right]$} & above $5 \%$ \\
Water & $0.05 \%$ \\
Isopropyl myristate $(\mathrm{IPM})$ & $0.004 \%$ \\
\hline
\end{tabular}

${ }^{a}$ The solubility of ACV in water and IPM are shown; ${ }^{b}$ Data taken from Moniruzzaman et al. (2010c)

difficult to dissolve into aqueous solution. On the other hand, the presence of a number of polar groups on the molecule is indicative of low solubility in apolar liquids, and even surfactant-rich or lipid-rich mixtures. Recently, a number of publications reported that ILs are capable of dissolving some important drugs molecules that are poorly soluble or insoluble in water and most of pharmaceutical accepted organic solvents (Anderson, 2003; Uzagare et al., 2003; Kumar et al., 2007; Moniruzzaman et al., 2010c) (for example see Table 1). The solubility of ILs depends on the properties of ILs. Although the cations of ILs have very little effect on the solubility, the anion has a significant influence on the solubility of drug molecules. Interestingly, it was reported that only hydrophilic ILs (possessing coordinating anions which are strong hydrogen bond acceptors) can dissolve drug molecules whereas hydrophobic ILs having noncoordinating anions could not (Kumar et al., 2007; Moniruzzaman et al., 2010c). This tendency of ILs is consistent with what was found in the case of solubilizing other sparingly soluble substrates (Swatloski et al., 2002). The results suggest that the dissolution of drug molecules in such ILs involves the formation of hydrogen bonds between the IL anions and the drug molecules (Uzagare et al., 2003; Moniruzzaman et al., 2010c). Uzagare et al. (2003) have studied the solubility of three ribonnucleosides (e.g., adenosine, cytosine and guanosine) in various ILs and compared the results found from commonly used organic solvents such as pyridine and DMF. Almost all the ILs showed better results in terms of solubility than that found in pyridine and DMF.

Florence and colleagues (Jaitely et al., 2008; Mizuuchi et al., 2008) have reported that RTILs or their mixtures can be used as a drug reservoir for the controlled release of poorly water soluble drugs. They have shown that the solubility of some poorly water soluble drugs can be increased markedly in ILs individually or in their mixtures. However, the solubility depends on the types of ILs as well as the types of drug molecules (see 
Table 2 Solubility of model drugs in RTILS (Mizuuchi et al., 2008)

\begin{tabular}{|c|c|c|c|c|}
\hline \multirow{2}{*}{ Solvent } & \multicolumn{4}{|c|}{ Solubility of Drug molecules $(\mathrm{mmol} / \mathrm{L}$, mean $\pm \mathrm{S} . \mathrm{D}, n=3)$} \\
\hline & Albendazole & Danazol & Acetaminophen & Caffeine \\
\hline$[\mathrm{bmim}]\left[\mathrm{BF}_{4}\right]$ & $1.49 \pm 0.02$ & $18.9 \pm 0.6$ & $>132$ & $84.0 \pm 2.0$ \\
\hline$[\mathrm{hmim}]\left[\mathrm{BF}_{4}\right]$ & $2.97 \pm 0.04$ & ND & ND & ND \\
\hline$[\mathrm{omim}]\left[\mathrm{BF}_{4}\right]$ & $7.20 \pm 0.30$ & $>59$ & $126 \pm 10$ & $83.0 \pm 3.0$ \\
\hline$[\mathrm{bmim}]\left[\mathrm{PF}_{6}\right]$ & $29.0 \pm 9.0$ & $11.9 \pm 0.20$ & $52 \pm 1$ & $100.0 \pm 11$ \\
\hline$[\mathrm{hmim}]\left[\mathrm{PF}_{6}\right]$ & $53.0 \pm 4.0$ & ND & ND & ND \\
\hline$[\mathrm{omim}]\left[\mathrm{PF}_{6}\right]$ & $>75$ & $35.0 \pm 5$ & $10 \pm 2$ & $34.0 \pm 7.0$ \\
\hline Water & $0.002 \pm 0.00008$ & $0.0003 \pm 00006$ & $98.8 \pm 0.7$ & $>102$ \\
\hline
\end{tabular}

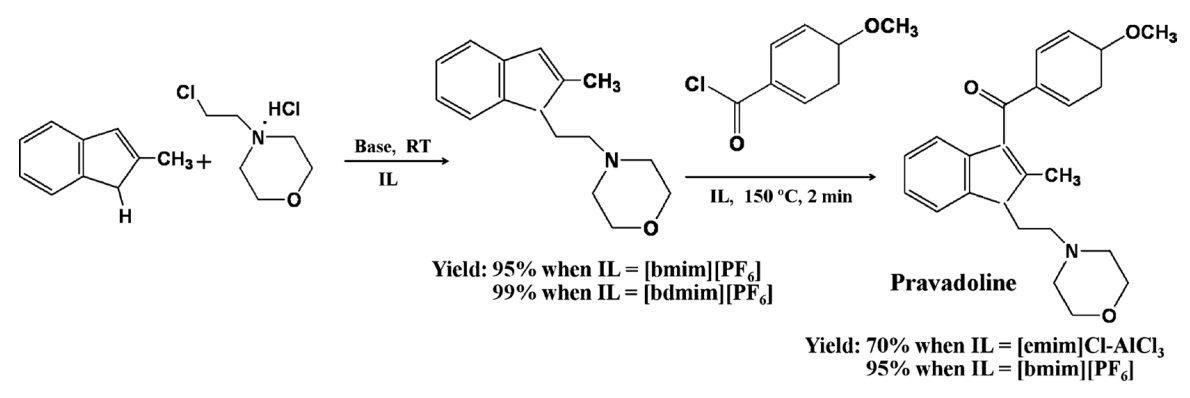

Fig. 2 Synthesis of Pravadoline (Earle et al., 2000)

Table 2). The authors reported that such solubility was achieved due to the appreciable drug-solvent interactions through hydrogen bonds, van der Waal's forces as well as $\pi-\pi$ interactions between aromatic rings as reported previously (Holbrey et al., 2003). The authors have also plotted the ternary phase diagram of water-miscible IL/water immiscible IL/water which indicated that the water miscibility of poorly water-miscible ILs could be improved by the inclusion of water-miscible ILs (Mizuuchi et al., 2008). This ability to modulate ILs aqueous miscibility expands their usefulness as pharmaceutical solvents. The drug release profiles show that sucrose and dexametasone from water-immiscible RTILs reservoirs into water can be prolonged over $48 \mathrm{~h}$. Interestingly, saturated solutions of $\left[\mathrm{bmim}^{\mathrm{b}}\right]\left[\mathrm{PF}_{6}\right]$ and $[\mathrm{hmim}]\left[\mathrm{PF}_{6}\right]$ showed little toxicity towards Caco- 2 cells (Jaitely et al., 2008).

\subsection{Synthesis of drug compounds in ionic liquids media}

Presently, pharmaceutical industries look forward to developing new technologies/methodologies in which the production of large quantities of waste products can be reduced. In most of the drug synthesis processes, organic solvents, particularly polar organic solvents, are employed. In such cases, the production of by-product with the desired products is very high (the weight ratio of by-product to desired products as 25-100 times is common in pharmaceutical industry). The organic solvents also produce many other problems as already mentioned previously. Hence, to find alternative approaches for the synthesis of drug compounds is essential.

In 2000, Earle et al., reported for the first time that ILs could be used as good reaction media for the synthesis of pharmaceutical compounds. They synthesized pharmaceutical pravadoline (see Figure 2) in IL [bmim] $\left[\mathrm{PF}_{6}\right]$ and $[\mathrm{bdmim}]\left[\mathrm{PF}_{6}\right]$ with $90-94 \%$ overall isolated yield in which the production of waste products was reduced significantly. The product was extracted from IL with toluene, which was distilled from the product and recycled. The IL also was recovered easily by simply washing with water and reused in the reactions after drying under vacuum. Following this study, the environmentally benign ILs started to be used in the synthesis of many useful drug compounds.

Nucleoside derivatives are effective antiviral drugs for the treatment of many viral infections, such as herpes simplex virus (HSV), human immunodeficiency (HIV), hepatitis B virus (HBC) and so on (Nasr et al., 1990; Mathe and Gosselin, 2006). They also have been used extensively as probes for diagnostic purposes and in antisense therapeutics. However, most of the nucleosides are insoluble in many organic solvents. This introduces a big problem in developing new methodologies to synthesis these nucleoside derivatives. Generally, aprotic solvents including pyridine, DMF and NMP, which are not considered as environmental benign solvents, are used in nucleoside chemistry and reportedly many problems are caused during synthesis processes. In recent years, ILs have been found to be excellent solvents for dissolution of nucleosides (Uzagare et al., 2003; Kumar et al., 2007; 


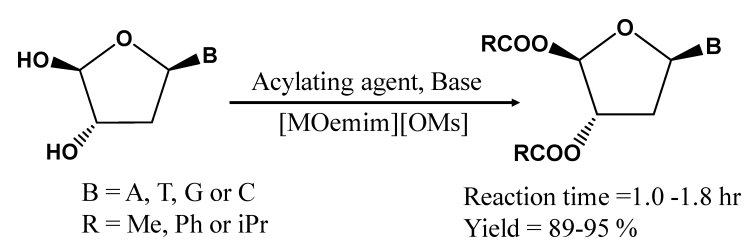

Fig. 3 Acylation of $2^{\prime}$-deoxyribonucleosides in IL[MOemim][OMs] (Uzagare et al., 2003)

Moniruzzaman et al., 2010c). This finding opens the door to using ILs as reaction media for synthesis of nucleoside analogs with many advantages over conventional solvents (Uzagare et al., 2003; Kumar and Malhotra, 2008, 2009; Zhang et al., 2009; Zang et al., 2011).

Uzagare et al. (2003) have reported on the acylation of $3^{\prime}$ - and $5^{\prime}$-functional groups of sugars and $\mathrm{NH}_{2}$ of base of 2'-deoxynucleosides in IL [MOemim][OMs] with different acylating agents including acetic anhydride, benzoyl chloride and isobutyryl chloride (see Figure 3). They used 1-methylimidazole (NMI) as a base and 4-(dimethylamino) pyridine as a catalyst. The system obtained a good yield (over 90\%) within a reaction time less than $2 \mathrm{~h}$. Notably, the products were easily isolated from IL simply by extracting with ethyl acetate. More interestingly, IL was recovered from the reaction mixture and reused without loss of product yield. In a following study, Prasad et al. (2005) carried out the similar reactions using benzoyl cyanide as a benzoylation agent and DMAP as a catalyst in IL [MOemim] [OMs] at $25-30^{\circ} \mathrm{C}$. The results indicated the selective benzoylation of sugar hydroxyl groups over amine group of nucleobase and produced O-benzoylated nucleoside derivatives with high yield. Later, Kumar et al. (2007) have expanded reaction media to another IL [MOemim][TFA] for benzoylation of 2'-deoxy-nucleosides using benzoic anhydride as acylating agents at $50^{\circ} \mathrm{C}$ and reported good yield of the products.

Recently, Kumar and Malhotra (2008) reported on the synthesis of nucleoside-based antiviral drugs including stavudine (d4T), brivudine (BVDU) and trifluridine (TFT) using three types of ILs (e.g., [MOemim][OMs], [MOemim][TFA] and [bmim][TFA]) and compared the results with what was found using conventional organic solvents such as DMA. The ILs were found to be better solvents for all the nucleosides in terms of the solubility and the reaction rates as compared to conventional molecular solvents (for example see Figure 4). Generally, tedious reaction conditions as well as longer reaction times are required for the synthesis of these drugs when organic solvents are used as reaction media (Lipahutz et al., 1995). In addition, the lower reaction volume of ILbased reactions makes the workup procedure very simple (generally, $10-15 \mathrm{~mL}$ of molecular solvent are required for $1 \mathrm{mmol}$ scale reaction whereas only $1.5 \mathrm{~mL}$ of ILs are needed for the same scale reactions). In fact, the high solubility of nucleoside substrates in ILs reduces

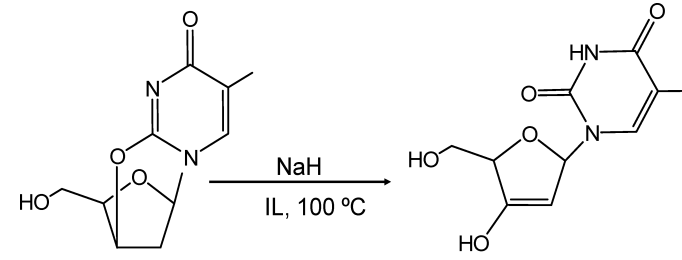

\begin{tabular}{lcc}
\hline Solvent & Time [min] & Yield [\%] \\
\hline DMA & 30 & 81 \\
[MOemim][OMs] & 10 & 89 \\
[MOemim][TFA] & 5 & 93 \\
[bmim][TFA] & 10 & 91 \\
\hline${ }^{a}$ Isolated yields & &
\end{tabular}

Fig. 4 Synthesis of d4T in ILs (Kumar and Malhotra, 2008)

\begin{tabular}{|c|c|c|c|c|}
\hline Entry & Solvent & $\begin{array}{c}\text { Temperature } \\
{\left[{ }^{\circ} \mathrm{C}\right]}\end{array}$ & $\begin{array}{l}\text { Reaction time } \\
{[\mathrm{h}]}\end{array}$ & $\begin{array}{l}\text { Yield } \\
{[\%]}\end{array}$ \\
\hline 1 & {$[\mathrm{bmim}]\left[\mathrm{PF}_{6}\right]$} & $\mathrm{rt}$ & 10 & 50 \\
\hline 2 & {$[\mathrm{bmim}]\left[\mathrm{PF}_{6}\right]$} & 50 & 8 & 76 \\
\hline 3 & {$[\mathrm{bmim}]\left[\mathrm{PF}_{6}\right]$} & 70 & 6 & 82 \\
\hline 4 & {$[\mathrm{bmim}]\left[\mathrm{PF}_{6}\right]$} & 80 & 5 & 87 \\
\hline 5 & {$[\mathrm{bmim}]\left[\mathrm{PF}_{6}\right]$} & 90 & 5 & 87 \\
\hline 6 & {$[\mathrm{bmim}]\left[\mathrm{BF}_{4}\right]$} & 80 & 8 & 74 \\
\hline 7 & $\mathrm{CH}_{2} \mathrm{Cl}_{2}$ & Reflux & 24 & 55 \\
\hline 8 & $\mathrm{EtOH}$ & Reflux & 24 & 10 \\
\hline 9 & THF & Reflux & 24 & 30 \\
\hline 10 & Toluene & Reflux & 8 & 85 \\
\hline
\end{tabular}

Reaction conditions: $1 \mathrm{mmol}$ of 1,2 , and 3; $1.5 \mathrm{~g}$ of IL for entries 1-6, whereas $4 \mathrm{~mL}$ of solvent for entries 7-10.

Fig. 5 Preparation of 2,3-disubstituted-1,3-thiazolidin-4where $\mathrm{R}_{1}=p-\mathrm{NO}_{2} \mathrm{C}_{6} \mathrm{H}_{4}, \mathrm{R}_{2}=p-\mathrm{CH}_{3} \mathrm{C}_{6} \mathrm{H}_{4}$ and $\mathrm{R}_{3}=\mathrm{H}$ (Zhang et al., 2009)

the solvent requirement. The same group also reported on the synthesis 5-halo derivatives (e.g., 5-halouridines and 5-halo-2'-deoxyuridines) of both protected and unprotected uridine $(\mathrm{U})$ and $2^{\prime}$-deoxyuridine $\left(2^{\prime}-\mathrm{dU}\right)$ in several types of ILs using lithium halide as halogenating agents, cerric ammonium nitrate (CAN) as oxidizing agents (Kumar and Malhotra, 2009). IL [MOemim] [OMs] was found to be the best solvent with the following optimized reaction conditions: $1.2 \mathrm{~mol}$ equivalent lithium iodide, $2.0 \mathrm{~mol}$ equivalent $\mathrm{CAN}$ and $80^{\circ} \mathrm{C}$. ILs were recovered and reused for up-to 4 cycles without any loss in yields.

Thiazolidinone and their derivatives have a wide range of biological activities such as antifungal, antihistaminic, antimicrobial activity and use in the treatment of inflammation. They are most conveniently made by the three-component condensation of a primary amine, an aldehyde and a mercapto acid (see Figure 5). Although 


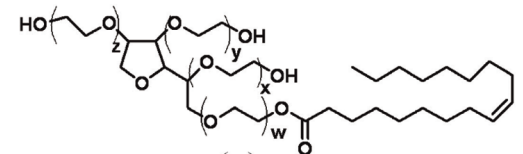

(a)

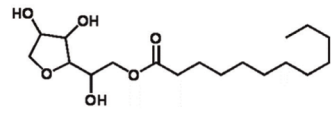

(b)

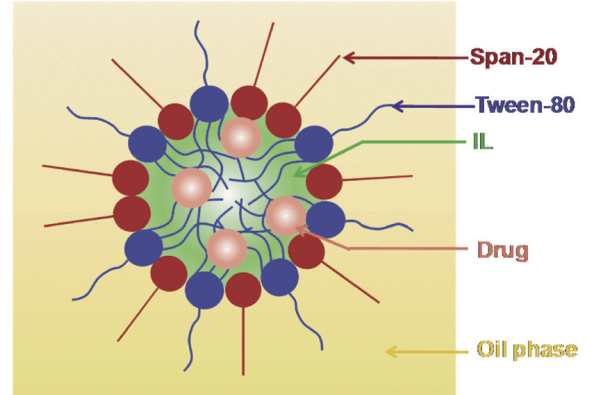

(c)

Fig. 6 Structure of surfactants: (a) Tween-80; (b) Span-20; (c) Schematic diagram of IL-in-oil MEs

various ways to synthesize thiazolidinones have been reported, there exist many limitations, such as using poisonous solvents, expensive catalysts, long reaction time and low or moderate yield. To address such drawbacks, Zhang et al. (2009) have developed a novel and an efficient procedure for the synthesis of a series of novel pyrimidine nucleoside-thiazolidin-4-one hybrids using ILs as a recyclable promoter and reaction media without use of any catalyst. The antiparasitic activities of some thiazolidins were also studied. They have studied the effect of the type of ILs on the condensation process for the synthesis of 2,3-distributed-1,3-thiazolinin-4-one derivatives and compared them with the results of conventional organic solvents (see Figure 5). Hydrophobic IL $[$ bmim $]\left[\mathrm{PF}_{6}\right]$ gave better results over hydrophilic IL $[\mathrm{bmim}]\left[\mathrm{BF}_{4}\right]$. However, both ILs were found to be better solvents as compared to organic solvents except toluene. Another beneficial point is that IL could be recycled at least five times without an obvious loss in its efficiency.

\subsection{Ionic liquid assisted nano-carrier for delivery of sparingly soluble drugs}

In Section 3.1, we discussed that many sparingly soluble drugs can be solubilized in ILs. For an example, hydrophilic ILs having coordinating anions (e.g., $\quad[\operatorname{dmim}]\left[(\mathrm{MeO})_{2} \mathrm{PO}_{2}\right], \quad[\mathrm{emim}]\left[(\mathrm{MeO})_{2} \mathrm{PO}_{2}\right]$ and [emim] [oAc]) are very effective in dissolution of acyclovir (Moniruzzaman et al., 2010c), which is an effective antiviral for the treatment of herpes simplex virus type 1 (HSV-1) and type 2 (HSV-2), varicella-zoster virus (VZV) and Epstein-Barr virus (EBV) (Schaeffer et al., 1978), is poorly soluble in water and most common organic solvents. We checked for any diffusion of ACV dissolved in ILs through the skin and found there was essentially zero possibly due to the hydrophobic barrier function of the skin, provided by the highly organized structure of the stratum corneum (Cevc, 2004). In addition, incorporation of a drug into a particulate carrier can protect it against degradation in vitro and in vivo, and the release can be controlled with specific targeting.

To meet these challenges, we have developed IL-inoil (IL/o) MEs - self-assembling colloidal particles in which a small amount of IL is dispersed in a large amount of oil in the presence of a surfactant (see Figure 6) that load drug molecules in the IL core and the continuous oil phase can be used to obtain the desired features for topical or/and transdermal transport behavior (Moniruzzaman et al., 2010c, 2010d, 2010e). It is well known that MEs, which are homogenous, transparent and thermo-dynamically stable dispersions of water and oil, stabilized by a surfactant or a blend of surfactants have emerged as prospective systems for drug delivery mainly due to their size, biocompatibility and straightforward preparation (Kogan and Garti, 2006; Gupta and Moulik, 2008). MEs with their supramolecular structure can increase not only the skin permeability, but also drug solubilization in the formulation and drug partitioning into the skin. Oil-soluble drugs can be formulated in $\mathrm{o} / \mathrm{w}$ MEs whereas, water-soluble ones are better suited to w/o systems. Consequently, stable IL/o MEs could lead to effective drug carriers for IL soluble drugs.

The formulation of IL/o MEs was composed of a blend of nontoxic surfactants, polyoxy-ethylene sorbitan monooleate (Tween-80) and sorbitan laurate (Span-20), isopropyl myristate (IPM) as an oil phase. It was found that hydrophilic ILs having coordinating anions can be solubilized in the core of Tween-80/Span-20/IPM micelles, whereas hydrophobic ILs containing nonco-ordinating anions (e.g., $\mathrm{PF}_{6}^{-},\left(\mathrm{CF}_{3} \mathrm{SO}_{2}\right)_{2} \mathrm{~N}^{-}$) are found to be very poorly soluble (Moniruzzaman et al., 2010d). Among hydrophilic ILs used, [dmim] $\left[(\mathrm{MeO})_{2} \mathrm{PO}_{2}\right]$ was found to be very effective as a disperse phase in the bulk IPM stabilized by a mixture of Tween-80 and Span-20. This system yields spherical micelles 8 to $34 \mathrm{~nm}$ in diameter, which are similar to those found in typical reverse micelles with water core stabilized by common surfactants (Pileni, 1989). The solubility studies of three sparingly soluble drugs molecules (i.e., acyclovir, methotrexate and dantrolene sodium) (Figure 7) indicated a high degree of drug solubilization in IL/o MEs, whereas various IL free systems can solubilize very small amounts of drugs (Moniruzzaman et al., 2010d). It was speculated that the successful dissolution of such sparingly soluble drug molecules in the IL/o MEs may 
<smiles>Nc1nc2c(COCCO)c[nH]c2c(=O)[nH]1</smiles><smiles>O=C1CN(/C=N/c2ccc(-c3ccc([N+](=O)[O-])cc3)o2)C(O[N+](=O)[O-])=N1</smiles>

1-[(5-(p-nitrophenyl) furfurylidene)) amino] hydantoin sodium (Dantrolene sodium)

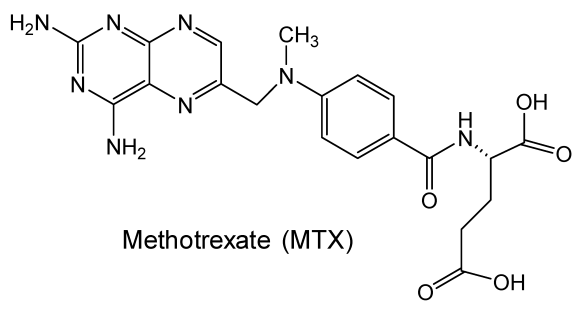

\begin{tabular}{lccc}
\hline \multirow{2}{*}{ Systems } & \multicolumn{3}{c}{ Drugs solubility $\left[\mathrm{mg} \mathrm{mL}^{-1}\right]$} \\
\cline { 2 - 4 } & ACV & MTX & Dantrolene soldium \\
\hline IL/o microemulsion & 4.98 & 6.90 & 3.65 \\
IL free micelles & 0.10 & 0.85 & 0.03 \\
w/o microemulsion & 0.30 & 1.20 & 0.18 \\
Water & 0.50 & 0.12 & 0.10 \\
IPM & 0.036 & 0.02 & ND \\
\hline
\end{tabular}

Fig. 7 Structure of drug molecules and their solubilities in various systems (Moniruzzaman et al., 2010d)

be attributed to the formation of hydrogen bonds between the IL anions and the polar groups of drug molecules. The IL/o MEs with drug molecules showed very good physical stability with storage time at various temperatures (Moniruzzaman et al., 2010e). Drug release from the new system was evaluated in vitro using full thickness skin pieces of Yucatan hairless micropigs (YMPs). The skin permeability of ACV into the skin was increased by several orders of magnitude, when IL/o MEs were used. More significantly, application of IL/o system induced significant transdermal permeation of $\mathrm{ACV}$, whereas other formulations showed essentially none (below our detection level) (see Table 3). The enhancement of ACV penetrations by using this new IL/o $\mathrm{ME}$ is thought to be due to the combination of factors including the high ACV solubility in IL disperse phase and the effect of lipophilic components.

To evaluate the relative safety of the IL/o MEs, the MTT cell viability assay was performed on the reconstructed human epidermal model Lab-Cyte ${ }^{\mathrm{TM}}$ EPIMODEL 12. The results demonstrated that a significant decrease in cell viability was observed when pure IL was used. However, ME containing $4 \mathrm{wt} \%$ IL showed over $80 \%$ in cell viability compared to control experiments (Moniruzzaman et al., 2010e). The same trend is consistent for many useful and necessary chemicals being used in the pharmaceutical industry. Although these cyto-toxicity results indicated that this newly developed IL/o MEs may be a safe TDD particularly for poorly soluble drugs,
Table 3 Acyclovir penetration into and across the skin using various formulations at $32.4^{\circ} \mathrm{C}$.

\begin{tabular}{lcc}
\hline Formulations & $\begin{array}{c}\text { Topical Delivery } \\
{\left[\mu \mathrm{g} / \mathrm{cm}^{3}\right]}\end{array}$ & $\begin{array}{c}\mathrm{TDD} \\
{\left[\mu \mathrm{g} / \mathrm{cm}^{2}\right]}\end{array}$ \\
\hline $\mathrm{IL}$ & $\mathrm{ND}$ & $\mathrm{ND}$ \\
$\mathrm{IPM}^{\mathrm{b}}$ & $0.18 \pm 0.34$ & $\mathrm{ND}$ \\
Surfactants $^{\mathrm{I}} \mathrm{IPM}^{\mathrm{c}}$ & $3.86 \pm 1.65$ & $\mathrm{ND}$ \\
w/o ME $^{\mathrm{b}, \mathrm{d}}$ & $4.57 \pm 3.17$ & $\mathrm{ND}$ \\
IL/o ME $^{\mathrm{ce}}$ & $10.78 \pm 3.12$ & $1.95 \pm 1.30$ \\
ACV cream $^{\mathrm{f}}$ & $1.21 \pm 0.10$ & $\mathrm{ND}$ \\
\hline
\end{tabular}

${ }^{a}$ all formulations contained $5 \mathrm{mg} / \mathrm{mL} \mathrm{ACV}$ and penetration time $24 \mathrm{~h} ;{ }^{\mathrm{b}}$ almost all ACV remained as suspended powders in formulations; ${ }^{c}$ the weight fraction of surfactants was $20 \mathrm{wt} \%$ (Tween-80: Span-20 =3:2 [w/w]; ${ }^{\mathrm{d}} \mathrm{w} / \mathrm{o}$ emulsion contained $4 \mathrm{wt} \%$ water; ${ }^{\mathrm{e}}$ the system containing $4 \mathrm{wt} \% \mathrm{IL} ;{ }^{\mathrm{f}} \mathrm{ACV}$ herpecia topical cream (equivalent to $5 \mathrm{mg} \mathrm{ACV}$ ) used for penetration study. All data taken from Moniruzzaman et al. (2010e)

a more nontoxic IL is required to explore these systems.

\subsection{Ionic liquids as active pharmaceutical ingredi- ents (APIs)}

Solid and crystalline forms of active pharmaceutical ingredients (APIs) have been traditionally used in drug formulations because of their improved properties with respect to solubility, purity, thermal stability and bioavailability. Such forms of drugs are also desirable for ease of handling and lower production and storage costs (Dutta and Grant, 2004). However, the solid form of many drugs has drawbacks that are mainly related to polymorphic conversion, low solubility, and low bioavailability for crystalline solids, and the tendency of amorphous forms to spontaneously crystallize (Hancock and Dalton, 1999). Considering these factors, researchers have paid attention to finding new physical drug forms, including salts, polymorphs, solvates, and co-crystals (Peterson et al., 2006).

In 2007, Rogers and co-workers have discovered that ILs could be used as active pharmaceutical ingredients (APIs) with new and unique properties compared to the solid pharmaceutical forms (Hough et al., 2007). They reported that hydrophobic RTIL [Lidocainium] [Docusate] (LD) prepared from lidocaine hydrochloride and sodium docusate showed modified solubility, increased thermal stability, and a significant enhancement in the efficacy of topical analgesia in two different models of mouse antinociception when compared to lidocaine hydrochloride. Following this interesting finding, researches on IL-based APIs have just begun (Hough and Rogers, 2007; Pamela et al., 2009; Bica et al., 2010; Stoimenovski et al., 2010). Figure 8 shows some of the reported IL-APIs with their physical properties.

IL-APIs can provide many advantages over solid or crystalline forms of drugs. IL-APIs can address the issue of polymorphism, a major problem in modern medicine. 
<smiles>CCCCCC(CC)(CCC)CCCC(COC(=O)CC(C(=O)OCC1CCC([18OH])O1)S(=O)(=O)[O-])NC</smiles>

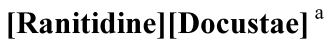

Function: histamine $\mathrm{H}_{2}$-receptor antagonist, emollient

Form: dark red liquid

$T_{\mathrm{m}}$ : liquid at RT

$T_{\mathrm{g}}:-12^{\circ} \mathrm{C}$<smiles>CCCCC(CC)(CCCC)COC(=O)CC(C(=O)OCC(CC)(CCC)CCCC)S(=O)(=O)[O-]</smiles>

[Lidocainium][Docustae ${ }^{\mathrm{a}}$

Function: pain reliever, emollient

Form: colorless gel

$T_{\mathrm{m}}$ : liquid at RT

$T_{\mathrm{g}}:-29^{\circ} \mathrm{C}$

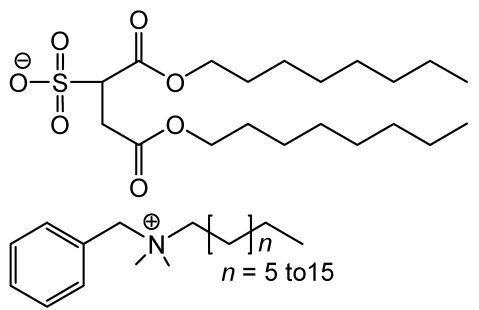

[Benzaalkonium][Colawet MA-80] ${ }^{\mathrm{b}}$

Function: antibacterial, anti-acne

Form: yellow gel

$T_{\mathrm{m}}$ : liquid at RT

$T_{\mathrm{g}}:-28^{\circ} \mathrm{C}$<smiles>CCCCCN(C)Cc1ccccc1</smiles>

[Benzaalkoium][Ibuprofenate] $^{\mathbf{b}}$

Function: antibacterial, anti-inflammatory

Form: yellow gel

$T_{\mathrm{m}}:-41^{\circ} \mathrm{C}$

$T_{\mathrm{g}}:-77^{\circ} \mathrm{C}$<smiles>CCCCCC[N+](C)(C)Cc1ccccc1</smiles>

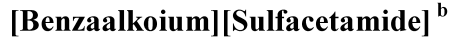

Function: antibacterial anti-acne

Form: yellow gel

$T_{\mathrm{m}}$ : liquid at RT

$T_{\mathrm{a}}: 46^{\circ} \mathrm{C}$

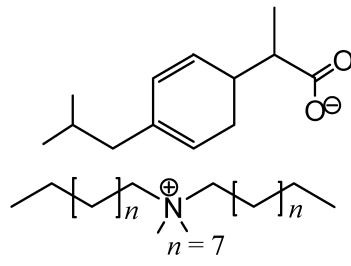

[Didecyldimethylammo nium][Ibuprofenate] ${ }^{b}$

Function: antibacterial, anti-acne

Form: yellow liquid

$T_{\mathrm{m}}$ : liquid at RT

$T_{\mathrm{g}}:-73^{\circ} \mathrm{C}$<smiles>CC(C)[N+](C)(CCOC(=O)C1c2ccccc2Oc2ccccc21)C(C)C</smiles>

[Propantheline]

[Acesulfamate] $^{\mathrm{c}}$

Function: antimuscarrinic, sweetener

Form: clear liquid

$T_{\mathrm{m}}$ : liquid at RT

$T_{\mathrm{g}}:-20^{\circ} \mathrm{C}$

Fig. 8 Some IL-APIs with their biological and physical properties. The synthesis and characterization can be found in references: ${ }^{\mathrm{a}}$ Hough et al., 2007; ${ }^{\mathrm{b}}$ Hough and Rogers $2007 ;{ }^{\mathrm{c}}$ Dean et al., 2009

For example, propantheline bromide is an antimuscarinic drug that can be present in different polymorphs (Borka and Halebian, 1990). However, it can easily combine with acesulfamate potassium (a calorie-free artificial sweetener) to form IL propantheline acesulfamate that will not suffer from polymorphism (Stoimenovski et al.,
2010). Similarly, IL-API ranitidine dosucate can avoid the polymorphism problem (Hough et al., 2007), although its starting material ranitidine hydrochloride has different polymorphs. Another advantage of IL-APIs is their controlled solubility. Since IL-APIs are composed of two biologically active ions (a cation and an anion), 
their solubility can be controlled by choosing the appropriate ions. Generally, strongly hydrophilic ionic actives do not pass into the biological membranes due to their highly hydrophobic nature (Heinrich and Wermuth, 2008). In the case of IL-APIs, the combination of such an active ion with another more hydrophobic active ion produces a hydrophobic IL-salt exhibiting reduced water solubility. For example, the solubility of IL [LD] in water was $1.24 \mathrm{mM}$, whereas the solubility of Lidocaine hydrochloride and Sodium docusate was $2488 \mathrm{mM}$ and $33.70 \mathrm{mM}$, respectively (Stoimenovski et al., 2010). More importantly, a number of delivery modes including topical and transdermal could be employed to deliver such hydrophobic liquid salts to the site of action more efficiently that dissolved crystalline APIs in a more concentrated and effective manner.

Very recently, Rogers and coworkers (Bica et al., 2010) have reported on an ionic liquid form of aspirin that could overcome the problems (e.g., poor solubility, bitter taste and large tablets required for the dosage) when solid aspirin is administered orally. Liquid aspirin was prepared by using simple ion exchange reactions between salts of the active component of aspirin (acetyl salicylate), or the chemically similar salicylic acid, and pharmaceutically active ammonium salts. The counter ions could be used to add a second function to the ionic liquid drug such as anti-bacterial or anti-microbial behavior. However, such ILs with aspirin show limited stability and slowly decompose into the corresponding salicylate ILs when exposed to moisture.

\subsection{Ionic liquids as antimicrobial agents}

In recent years, ILs have been increasingly exploited as potential antimicrobial agents possibly due to their toxicity, an important tunable characteristic. In fact, this property allows for appropriate design of ILs that could be used as new and improved antiseptics, disinfectants and anti-fouling reagents. To date, a number of publications have highlighted the antimicrobial activity of imidazolium, pyridinium and quaternary ammonium ILs against both environmental and clinically important micro-organism (Pernak et al., 2003, 2004b, 2004c; Pernak and Feder-Kubis, 2005; Docherty and Kulpa, 2005; Carson et al., 2009; Hough-Troutman et al., 2009; Busetti et al., 2010). For example, Pernak and co-workers evaluated the antimicrobial activity of a series of 3alkoxymethyl-1-methylimidazolium ILs with different anions, (Pernak et al., 2003) 1,3-(dialkyloxymethyl)substituted imidazolium ILs with different anions (Pernak et al., 2004b) and 1-alkylimidazolium and 1alkoxymethyl-imidazolium protic ILs with lactate anion (Pernak et al., 2004c) against clinically significant pathogens (rods, cocci and fungi). It was found that the antimicrobial activities of ILs are strongly dependent on the length of the substituent alkyl chain. Ionic liquids containing longer $(\geq 10)$ carbon substituents showed very high antimicrobial activities. A similar trend was observed when antifungal and antibacterial activities of imidazolium based ILs with various anions was examined against bacteria and fungi (Luczak et al., 2010). However, changing the type of anion produced smaller effect on antimicrobial activities.

In another recent study, Carson et al. (2009) have reported on the antibiofilm and antimicrobial activity of a series of 1-alkyl-3-methylimidazolium chloride ILs against a panel of pathogen microorganism, including MRSA (Methicillin-resistant Staphylococcus aureus) and other pathogens associated with hospital acquired infections. Clinically, microbial biofilms are extremely problematic and in general, such biofilms protect infectious microorganisms from antiseptics, disinfectants, and antibiotics. However, ILs can break down microbial biofilms easily to destroy microorganisms such as MRSA. It was found that antibiofilm potency increased with the length of the alkyl chain. In a subsequent study, Busetti et al. (2010) have reported the antimicrobial and antibiofilm activities of 1-alkylquinolinium bromide ILs $\left[\mathrm{C}_{n}\right.$ quin $][\mathrm{Br}]$ against a range of clinically relevant microorganisms, both planktonic and sessile (biofilm) cultures. It is well known that quinoline derivatives have been used extensively as antibacterial, antifungal and antimalarial agents (Larsen et al., 1996; Azad et al., 2007). All ILs exhibited excellent, broad spectrum antimicrobial activity expressed minimum inhibitory concentrations (MIC) and minimum bactericidal/fungicidal concentration (MBC). However, optimized antimicrobial activity was highly dependent on the length of alkyl substituents appended in the cation of ILs as shown in Table 4 for both Gram positive cocci and Gram negative rods and fungi (Carson et al., 2009; Busetti et al., 2010). These studies certainly indicate that using the tunability of ILs, antimicrobial agents for particular application or for specified microorganisms could be prepared.

\section{Conclusions}

The results discussed in this review article clearly demonstrate that ionic liquids could be very effective solvents and/or agents in pharmaceuticals. The use of ILs as solvents for the synthesis of drugs, in particular, nucleoside-based antiviral drugs providing many advantages, such as milder reaction conditions, low solvent consumption, easy workup and less waste production. The high solubility of many sparingly soluble drugs in some ionic liquids could open up new functionalization methodology for effective delivery them that are not possible in conventional solvents. One of the most appealing features of ILs for pharmaceutical applications is their use as active pharmaceutical ingredients with some attractive properties. However, additional studies are required to obtain biologically and physically robust data to predict the proper design for pharmaceutically IL-APIs. The main drawback of using ILs is the significant uncertainty regarding the toxicity, biodegradability and potential impact of ILs on the environment. 
Table 4 MIC and MBC values of $\left[\mathrm{C}_{n} \mathrm{mim}\right][\mathrm{Cl}]$ (Carson et al., 2009) and $\left[\mathrm{C}_{n}\right.$ quin $][\mathrm{Br}]$ (Bustti et al., 2010)

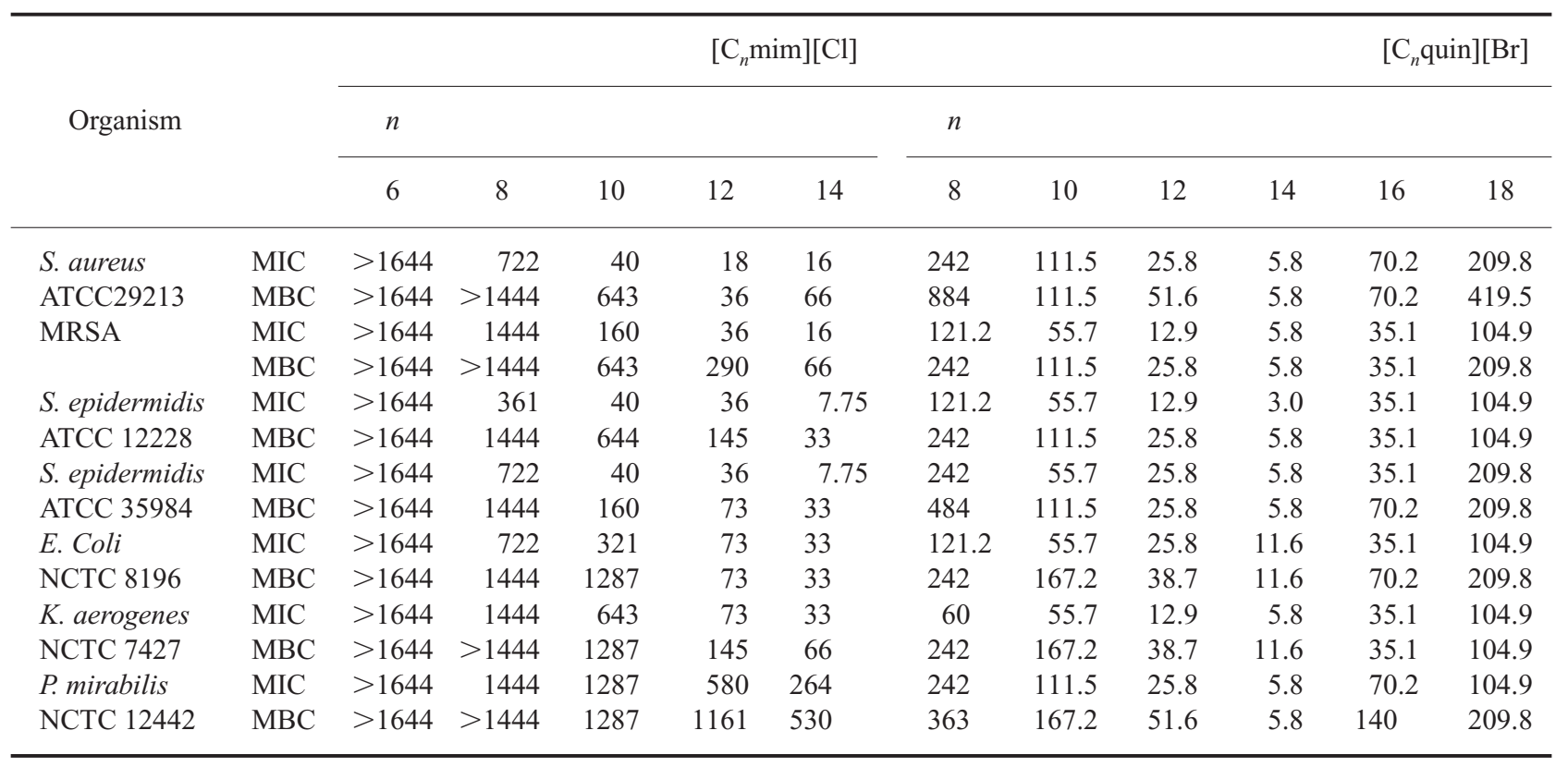

However, in both of these areas significant steps have been made in the understanding and creation of cleaner routes to the preparation of ILs. We believe that green and biocompatible ILs will be available in the near future, which will stimulate the use of ILs in pharmaceutical applications.

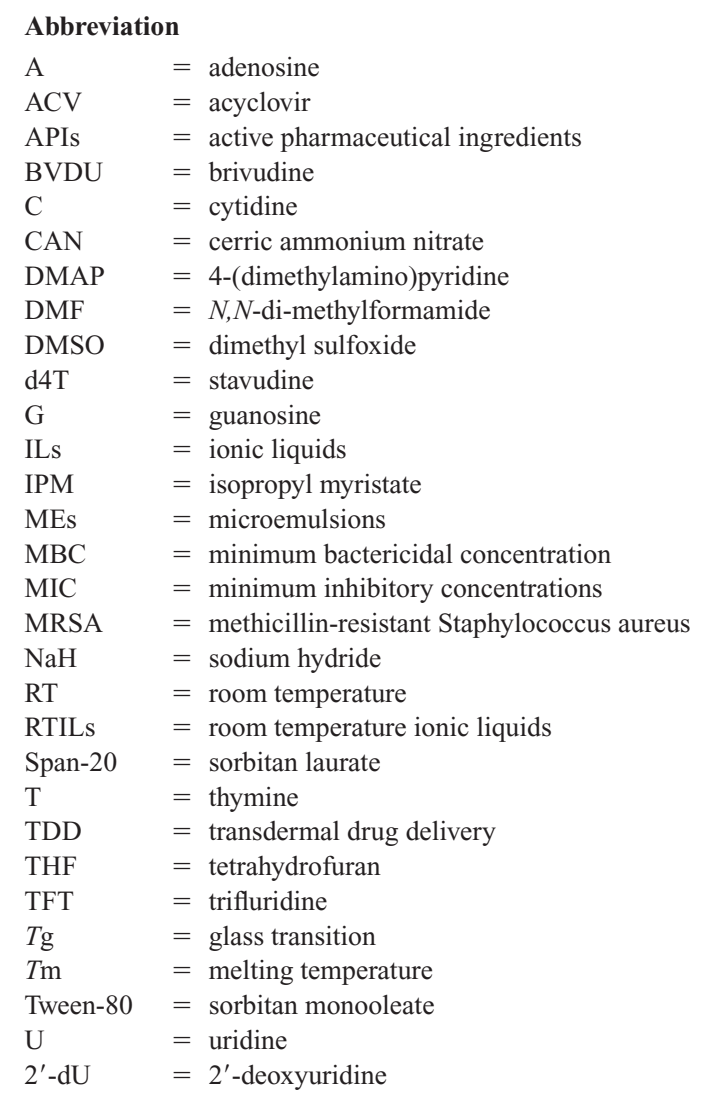

$\begin{array}{ll}\mathrm{IL} / \mathrm{o} & =\text { ionic liquid-in-oil } \\ \mathrm{w} / \mathrm{O} & =\text { water-in-oil } \\ \mathrm{o} / \mathrm{w} & =\text { oil-in-water }\end{array}$

\section{Ionic liquids cations and anions}

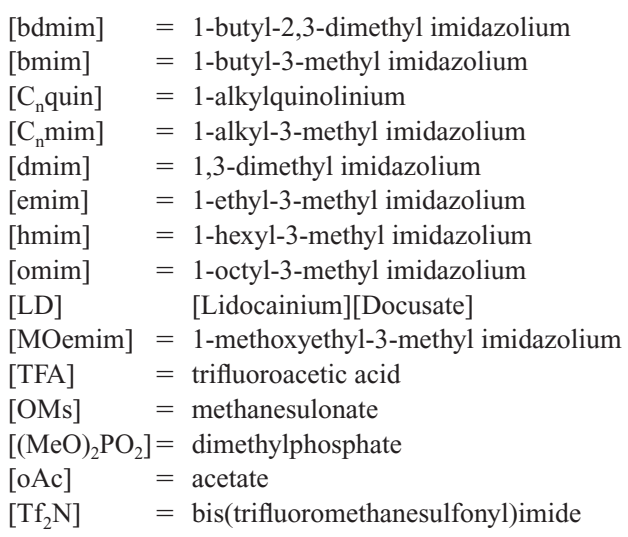

\section{Literature Cited}

Anderson, D. M.; "Solvent Systems," US Patent 000057-A1 (2003)

Anderson, J. L. and D. W. Armstrong; "Immobilized Ionic Liquids as High-Selectivity/High-Temperature/High Stability Gas Chromatography Stationary Phases," Anal. Chem., 77, 6453-6462 (2005)

Anderson, J. L., J. Ding, T. Welton and D. W. Armstrong; "Characterizing Ionic Liquids on the Basis of Multiple Solvation Interactions," J. Am. Chem. Soc., 124, 14247-14254 (2002)

Azad, M., M. A. Munawar and H. L. Siddiqui; "Antimicrobial Activity and Synthesis of Quinoline Based Chalcones," J. Appl. Sci., 7, 2485-2489 (2007)

Belieres, J. P., D. Gervasio and C. A. Angell; "Binary Inorganic Salt Mixtures as High Conductivity Liquid Electrolytes for $>100^{\circ} \mathrm{C}$ Fuel Cells," Chem. Commun., 4799-4801 (2006)

Bica, K., C. Rijksen, M. Nieuwenhuyzen and R. D. Rogers; "In Search 
Liquid Salts Forms of Aspirin: Ionic Liquid Approaches with Acetylsalicyclic Acid and Salicylic Acid," Phys. Chem. Chem. Phys., 12, 2011-2017 (2010)

Borka L. and J. K. Haleblian; "Crystal Polymorphism of Pharmaceuticals," Acta Pharm. Jugosl., 40, 71-94 (1990)

Busetti, A., D. E. Crawford, M. J. Earle, M. A. Gilea, B. F. Gilmore, S. P. Gorman, G. Laverty, A. F. Lowry, M. McLaughlin and K R. Seddon; "Antimicroviral and Antibiofilm Activities of 1alkylquinolinium Bromide Ionic Liquids," Green Chem., 12, 420-425 (2010)

Carson, L., P. K. W. Chau, M. J. Earle, M. A. Gilea, B. F. Gilmore, S. P. Gorman, M. T. McCann and K. R. Seddon; "Antibiofilm Activities of 1-alkyl-3-methyl-imidazolium Chloride Ionic Liquids," Green Chem., 11, 492-497(2009)

Cevc, G.; "Lipid Vesicles and Other Colloids as Drug Carriers on the Skin," Adv. Drug. Delivery Rev., 56, 675-711 (2004)

Coleman, D. and N. Gathergood; "Biodegradation Studies of Ionic Liquids," Chem. Soc. Rev., 39, 600-637(2010)

Constable, D. J. C., C. Jimenez-Gonzalez and R. K. Henderson; "Perspective on Solvent Use in the Pharmaceutical Industry," Org. Process Res. Dev., 11, 133-137 (2007)

Dean, P. M., J. Turanjanin, M. Y. Fujita, D. R. MacFarlane and J. L. Scott; "Exploring an Anti-Crystal Engineering Approach to the Preparation of Pharmaceutically Active Ionic Liquids," Cryst. Growth Des., 9, 1137-1145 (2009)

Docherty, K. M. and C. F. Kulpa; "Toxicity and Antimicrobial Activity of Imidazolium and Pyridinium Ionic Liquids," Green Chem., 7, 185-189 (2005)

Dutta, S. and D. J. W. Grant; “Crystal Structures of Drugs: Advances in Determination, Prediction and Engineering," Nat. Rev. Drug Discovery, 3, 42-57 (2004)

Earle, M. J., P. B. McCormac and K. R. Seddon; "The First High Yield Green Route to a Pharmaceutical in a Room Temperature Ionic Liquids," Green Chem., 2, 261-262 (2000)

Ford, L, J. R. Harjani, F. Atefi, M. T. Garcia, R. D. Singer and P. J. Scammells; "Further Studies on the Biodegradation of Ionic Liquids," Green Chem., 12, 1783-1789 (2010)

Fujita, K., D. R. MacFarlane and M. Forsyth; "Protein Solubilising and Stabilising Ionic Liquids,” Chem. Commun., 4804-4806 (2005)

Fujita, K., M. Forsyth, D. R. MacFarlane, R. W. Reid and G. D. Elliott; "Unexpected Improvement in Stability and Utility of Cytochrome c by Solution in Biocompatible Ionic Liquids," Biotechnol. Bioeng., 94, 1209-1213 (2006)

Fukaya, Y., K. Hayashi, M. Wada and H. Ohno; "Cellulose Dissolution with Polar Ionic Liquids Under Mild Conditions: Required Factors for Anions," Green Chem., 10, 44-46 (2008)

Gathergood, N., M. T. Garcia and P. J. Scammells; "Biodegradable Ionic Liquids: Part I. Concept, Preliminary Targets and Evaluation," Green Chem., 6, 166-175 (2004)

Gupta, S. and S. P. Moulik; "Biocompartible Microemulsions and Their Prospective Uses in Drug Delivery," J. Pharm. Sci., 97, 22-45 (2008)

Hancock, B. C. and C. R. Dalton; "The Effect of Temperature on Water Vapor Sorption by Some Amorphous Pharmaceutical Sugars," Pharm. Dev. Technol., 4, 125-131 (1999)

Harada, M., Y. Kimura, K. Saijo, T. Ogawa and S. Isoda; "Photochemical Synthesis of Silver Particles in Tween 20/Water/Ionic Liquid Microemulsions," J. Colloid Interface Sci., 339, 373-381 (2009)

Heinrich, S. P. and C. G. Wermuth eds.; Handbook of Pharmaceutical Salts; Properties, Selection, and Use, VHCA and Wiley-VCH, Weinheim, Germany (2008)

Holbrey, J. D., W. M. Reichert, M. Nieuwenuyzen, O. Sheppard, C. Hardacre and R. D. Rogers; "Liquid Clathrate Formation in Ionic Liquid Aromatic Mixtures," Chem. Commun., 476-477 (2003)

Hough, W. L. and R. D. Rogers; "Ionic Liquids Then and Now: From Solvents to Materials to Active Pharmaceutical Ingredients," Bull. Chem. Soc. Jpn., 80, 2262-2269 (2007)

Hough, W. L., M. Smiglak, H. Rodríguez, R. P. Swatloski, S. K. Spear,
D. T. Daly, J. Pernak, J. E. Grisel, R. D. Carliss, M. D. Soutullo, Jr., J. H. Davis and R. D. Rogers; "The Third Evolution of Ionic Liquids: Active Pharmaceutical Ingredients," New J. Chem., 31, 1429-1436 (2007)

Hough-Troutman, W. L., M. Smiglak, S., Griffin, W. M. Reichert, I. Mirska, J. Jodynis-Liebert, T. Adamska, J. Nawrot, M. Stasiewicz, R. D. Rogers and J. Pernak; "Ionic Liquids with Dual Biological Function: Sweet and Antimicrobial, Hydrophobic Quaternary Ammonium-based Salts," New J. Chem., 33, 26-33 (2009)

Jaitely, V., A. Karatas and A. T. Florence; "Water-Immiscible Room Temperature Ionic Liquids (RTILs) as Drug Reservoirs for Controlled Release," Int. J. Pharm., 354, 168-173 (2008)

Jastorff, B., K. Moelter, P. Behrend, U. Bottin-Weber, J. Filser A. Heimers, B. Ondruschka, J. Ranke, M. Schaefer, H. Schroeder, A. Stark, P. Stepnowski, F. Stock, R. Stoermann, S. Stolte, U. Welz-Biermann, S. Ziegert and J. Thoeming; "Progress in Evaluation of Risk Potential of Ionic Liquids Basis for an Eco-design of Sustainable Products," Green Chem., 7, 362-372 (2005)

Kogan, A. and N. Garti; "Microemulsions as Transdermal Drug Delivery Vehicles," Adv. Colloid Interface Sci., 123-126, 369-385 (2006)

Kosmulski, M., J. Gustafsson and J. B. Rosenholm; "Thermal Stability of Low Temperature Ionic Liquids Revisited," Thermochim. Acta, 412, 47-53 (2004)

Kumar, V. and S. V. Malhotra; "Synthesis of Nucleoside-based Antiviral Drugs in Ionic Liqids," Bioorg. Med. Chem. Lett., 18, 5440-5642 (2008)

Kumar, V. and S. V. Malhotra; "Ionic Liquid Mediated Synthesis of 5halouracil Nucleosides: Key Precursors for Potential Antiviral Drugs," Nucleosides Nucleotides Nucleic Acids, 28, 821-834 (2009)

Kumar, V., V. S. Parmar and S. V. Malhotra; "Enahanced Solubility and Selective Bezoylation of Nucleosides in Novel Ionic Liquids," Tetrahedron Lett., 48, 809-812 (2007)

Larsen, D., E. G. Corley, A. O. King, J. D. Carrol, P. Davis, T. R. Verhoeven, P. J. Reider, M. Labelle, J. Y. Gauthier, Y. B. Xiang and R. Zamboni; "Practical Route to a New Class of LTD $_{4}$ Receptor Antagonists," J. Org. Chem., 61, 3398-3405 (1996)

Lipahutz, B. H., K. L. Stevens and R. F. Lowe; "A Novel Route to the Anti-HIV Nucleoside d4T," Tetrahedron Lett., 36, 2711-2712 (1995)

Lipinski, C. A., F. Lombardo, B. W. Dominy and P. J. Feeney; "Experimental and Computational Approaches to Estimate Solubility and Permeability in Drug Discovery and Development Settings," Adv Drug Delivery Rev., 46, 3-26 (2001)

Łuczak, J., C. Jungnickel, I. Łacka, S. Stoltec and J. Hupka; "Antimicrobial and Surface Activity of 1-alkyl-3-methylimidazolium Derivatives," Green Chem., 12, 592-601 (2010)

Mathe, C. and G. Gosselin; "L-Nucleoside Enantiomers as Antrivirals Drugs: A Mini Review," Antiviral Res., 71, 276-281 (2006)

Mizuuchi, H., V. Jaitely, S. Murdan and A. T. Florence; "Room Temperature Ionic Liquids and Their Mixtures: Potential Pharmaceutical Solvents," Eur. J. Pharm. Sci., 33, 326-331(2008)

Moniruzzaman, M., K. Nakashima, N. Kamiya and M. Goto; "Recent Advances of Biocatalytic Reactions in Ionic Liquids," Biochem. Eng. J., 48, 295-314 (2010a)

Moniruzzaman, M., N. Kamiya and M. Goto; "Activation and Stabilization of Enzymes in Ionic Liquids," Org. Biomol. Chem., 8, 2887-2899 (2010b)

Moniruzzaman, M., Y. Tahara, M. Tamura, N. Kamiya and M. Goto; "Ionic Liquid Assisted Transdermal Delivery of Sparingly Soluble Drugs," Chem. Commun., 47, 1452-1454 (2010c)

Moniruzzaman, M., N. Kamiya and M. Goto; "Ionic Liquid Based Microemulsion with Pharmaceutically Accepted Components: Formulation and Potential Applications," J. Colloid Interface Sci., 352, 136-142 (2010d)

Moniruzzaman, M., M. Tamura, Y. Tahara, N. Kamiya and M. Goto; "Ionic Liquid-in-Oil Microemulsion as a Potential Carrier of 
Sparingly Soluble Drug: Characterization and Cytotoxicity Evaluation," Int. J. Pharm., 400, 243-250 (2010e)

Morrissey, S., B. Pegot, D. Coleman, M. T. Garcia, D. Ferguson, B. Quilty and N. Gathergood; "Biodegradable, Non-bactericidal Oxygen-functionalised Imidazolium Esters: A Step Towards 'Greener' Ionic Liquids,' Green Chem., 11, 475-483 (2009)

Nasr, M., C. Litterst and J. McGowan; "Computer-Assisted StructureActivity Correlations of Dideoxynucleoside Analogs as Potential Anti-HIV Drugs," Antiviral. Res., 14, 125-148 (1990)

Pamela, M. D., J. Turanjanin, M. Y. Fujita, D. R. MacFarlane and J. L. Scott; "Exploring an Anti-Crystal Engineering Approach to the Preparation of Pharmaceutically Active Ionic Liquids," Cryst. Growth Des., 9, 1137-1145 (2009)

Pernak, J. and J. Feder-Kubis; "Synthesis and Properties of Chiral Ammonium-based Ionic Liquids," Chem. Eur. J., 11, 4441-4449 (2005)

Pernak, J., A. Czepukowicz and R. Pozniak; "New Ionic Liquids and Their Antielectrostatic Properties," Ind. Eng. Chem. Res., 40, 2379-2383 (2001)

Pernak, J., K. Sobaszkiewicz and R. Mirska; "Antimicrobial Activities of Ionic Liquids," Green Chem., 5, 52-56 (2003)

Pernak, J., P. Chwala and A. Syguda; "Room Temperature Ionic Liquids-New Choline Derivatives," Pol. J. Chem., 78, 539-546 (2004a)

Pernak, J., K. Sobaszkiewicz and J. Foksowicz-Flaczyk; "Ionic Liquids with Symmetrical Dialkoxymethyl-substituted Imidazolium Cations," Chem. Eur. J., 10, 3479-3485 (2004b)

Pernak, J., I. Goc and R. Mirska; "Antimicrobial Activities of Protic Ionic Liquids with Lactate Anion," Green Chem., 6, 323-329 (2004c)

Peterson, M. L., M. B. Hickey, M. J. Zaworotko and O. Almarsson; "Expanding the Scope of Crystal Form Evaluation in Pharmaceutical Science," J. Pharm. Pharmaceut. Sci., 9, 317-326 (2006)

Petkovic, M., J. L. Ferguson, H. Q. N. Gunaratne, R. Ferreira, M. C. Leitao, K. R. Seddon, L. P. N. Rebelo and C. S. Pereira; "Novel Biocompatible Cholinium-based Ionic Liquids-Toxicity and Biodegradability," Green Chem., 12, 643-649 (2010)

Pileni, M.; Structure and Reactivity in Reverse Micelles, Elsevier, Amsterdam, the Netherlands (1989)

Prasad, A. K., V. Kumar, S. Malhotra, V. T. Ravikumar, Y. S. Sanghvi and V. S. Parmar; "Green Methodology for Efficient and Selective Benzoylation of Nucleosides Using Benzoyl Cyanide in an Ionic Liquid," Bioorg. Med. Chem., 13, 4467-4472 (2005)

Rantwijk, F. van and R. A. Sheldon; "Biocatalysis in Ionic Liquids," Chem. Rev., 107, 2757-2785 (2007)

Rogers, R. D. and K. R. Seddon; Ionic Liquids; Industrial Applications for Green Chemistry. ACS Symposium Series 818, American
Chemical Society, Washington, DC, U.S.A. (2002)

Schaeffer, H. J., L. Beauchamp, P. de Miranda, G. B. Elion, D. J. Bauer and P. Collins; "9-(2-Hydroxyethoxymethyl)Guanine Activity Against Viruses of the Herpes Group," Nature, 272, 583-585 (1978)

Stoimenovski, J., D. R. MacFarlane, K. Bica and R. D. Rogers; "Crystalline vs. Ionic Liquid Salt Forms of Active Pharmaceutical Ingredients: A Positive Paper," Pharm. Res., 27, 521-526 (2010)

Stolte, S., M. Matzke, J. Arning, A. Boeschen, W. R. Pitner, U. Welz-Biermann, B. Jastorff and J. Ranke; "Effects of Different Head Groups and Functionalised Side Chains on the Aquatic Toxicity of Ionic Liquids," Green Chem., 9, 1170-1779 (2007)

Swatloski, R. P., S. K. Spear, J. D. Holbrey and R. D. Rogers; "Dissolution of Cellulose with Ionic Liquids," J. Am. Chem. Soc., 124, 4974-4975 (2002)

Swatloski, R. P., J. D. Holbrey, S. B. Memom, G. A. Caldwell, K. A. Caldwell and R. D. Rogers; "Using Caenorhabditis elegans to Probe Toxicity of 1-alkyl-3-methylimidazolium Chloride Based Ionic Liquids," Chem. Commun., 668-669 (2004)

Uzagare, M. C., Y. S. Sanghvi and M. M. Salunkhe; "Application of Ionic Liquids 1-methoxyethyl-3-methyl imidazolium Methanesulfonate in Nucleoside Chemistry," Green Chem., 5, 370-372 (2003)

Vidis, A., C. A. Ohlin, G. Laurenczy, E. Kusters, G. Sedelmeier and P. J. Dysona; "Rationalisation of Solvent Effects in the Diels-Alder Reaction Between Cyclopenta-diene and Methyl Acrylate in Room Temperature Ionic Liquids," Adv. Synth. Catal., 347, 266-274 (2005)

Visser, A. E., R. P. Swatloski, S. T. Griffin, D. H. Hartman and R. D. Rogers; "Liquid/Liquid Extraction of Metal Ions in Room Temperature Ionic Liquids," Sep. Sci. Technol., 36, 785-804 (2001)

Welton, T.; "Room Temperature Ionic Liquids. Solvents for Synthesis and Catalysis," Chem. Rev., 99, 2071-2084 (1999)

Wood, N. and G. Stephens; "Accelerating the Discovery of Biocompatible Ionic Liquids," Phys. Chem. Chem. Phys., 12, 1670-1674 (2010)

Yalkowaky, S. H. ed.; Techniques of Solubilization of Drugs, Marcel Dekker, New York, U.S.A. (1981)

Zhang, X., X. Li, D. Li, G. Qu, J. Wang, P. M. Loiseau and X. Fan; "Ionic Liquid Mediated and Promoted Eco-friendly Preparation of Thiazolidinone and Pyrimidine Nucleoside-thiazolidinone Hybrids and Their Antiparasitic Activities," Bioorg. Med. Chem. Lett., 19, 6280-6283 (2009)

Zang, H., Q. Su, Y. Mo and B. Cheng; "Ionic Liquid Under Ultrasonic Irradiation Towards a Facile Synthesis of Pyrazolone Derivatives," Ultrason. Sonochem., 18, 68-72 (2011) 